\title{
Climate Change and Nutrition
}

Niamh Kelly ANutr, BSc Human Nutrition, Policy Research Officer in Sustainable Food Systems, London School of Hygiene \& Tropical Diseases, UK niamh.kelly1@student.Ishtm.ac.uk

\begin{abstract}
Human health and planetary health are intertwined in many ways, food systems being an example. This article describes the complex manner in which food systems impact on the environment and how our dietary choices have consequences for climate change. Subsequent changes to weather patterns and ecosystems can then destabilise these food systems impacting on human health. This article explains how various components of food systems must be considered when attempting to understand effects on climate change. It concludes by offering practical solutions on an individual and societal level to mitigate these effects.
\end{abstract}

\section{Key words}

Climate change, nutrition, food systems, sustainability

Cite as: Kelly N. Climate Change and Nutrition. Sushruta 2020 (Jul) 13(2): pre-print v1 ePub 23.04.2020 DOI: $\underline{10.38192 / 13.2 .8}$

\section{Climate change and Nutrition}

The recent COVID-19 pandemic has brought into focus the link between human health and planetary health. This is something we need to keep in mind once we make it through this crisis and ensure that we move forward in a way that benefits both human health and the environment. One area that needs particular attention is food; our food systems have a tremendous impact on the environment, accounting for $20-30 \%$ of total global greenhouse gas emissions (1). Food systems include everything that happens to our food from farm to fork such as the agricultural practices used, processing, transport and food waste. However, these different aspects of the food system don't contribute equally to climate change. About two thirds of emissions linked to our food are from the agricultural side of food production, mainly from livestock and changes in land use for farming. The remaining third is accrued during processing, packaging and transport.

\section{Livestock and Land use}

Livestock alone produce approximately $15 \%$ of overall GHG emissions, mainly due to methane production from cattle and sheep, but also includes contributions from feed production and changes in land use for grazing. Large areas are deforested each year to convert the space into pasture for animals to graze, or crops to be grown. Forests are considered "carbon sinks" which means they are good for soaking up carbon from the atmosphere. Therefore, removing 
large amounts of forests reduces the amount of carbon dioxide being absorbed, but can also lead to carbon dioxide actually being released into the atmosphere when the trees are cut down.

\section{Water use}

Water used in agriculture is a combination of stored rainwater (called "green" water) and groundwater which is found in the spaces between soil and rocks underground. We are increasingly reliant on groundwater in agriculture, particularly in India where $90 \%$ of groundwater is used for agriculture. As temperatures rise and incidence of drought increases in certain areas more water will be needed to produce crops, particularly those such as almonds and avocados which are grown in dry, hot areas and require a lot of water.

\section{Transport}

Half of the food consumed in the UK is imported, adding extra emissions to our food system (2). About one third of UK food is imported from Europe and the other $20 \%$ comes from various regions including Africa, South America and Asia. Fruit and vegetables are the main types of foods imported, partly due to the demand for certain fruits and vegetables all year round, rather than when they are in season. However, this is a complex issue and there are times when transporting foods from abroad in fact has lower emissions than locally produced foods. For example, growing tomatoes in the UK under heated conditions can be more energy intensive than those grown in Spain (1).

\section{Biodiversity}

Biodiversity, or the variability of species in a region, is an important part of planetary health as each species place a role in sustaining ecosystems. One of the main drivers of loss of biodiversity is changes in land use, such as deforestation and changes in land use for farming, which can destroy animal habitats. As well as this, some agricultural processes are putting some of our pollinators such as honeybees as risk. In the United States a large portion of the honeybee population are transported to California by beekeepers each year to pollinate almond trees. It is risky bringing such a large proportion of one species to one location as if they came in contact with a pathogen, there is the potential for the bee population to be depleted (3).

\section{How climate change can affect our food systems}

There has been an increasing occurrence of extreme weather events like floods, forest fires and drought in recent years, which can have major impacts on food production and supply. However, these events and the warming of the planet is not happening evenly. Low- and middle-income countries, which hold most of the world's population, are more vulnerable to climate change than high income countries and have already begun seeing some of its affects. Additionally, a modelling study carried out in 2016 by Springman and colleagues predicts that by 2050 there will be a $3.2 \%$ reduction in food availability, which consists mainly of reductions in fruit and vegetables, and these effects will predominantly be seen in Africa, Southeast Asia and Western Pacific Regions (4). 
Rising temperatures will increase the demand for water for use in agriculture, particularly in drought prone areas. Seasonal patterns have begun to shift slightly and this along with changes in rainfall and temperatures makes harvests unpredictable and can lead to spoilage and food loss. This dysregulation can also negatively affect insect pollinators which may begin to migrate to other areas that have a more suitable climate.

It is difficult to predict each way climate change may affect our food supplies but there is some debate over whether climate change may impact the nutrition quality of foods, or whether some crop pests and diseases may become more virulent (5). Due to our widespread use of monocropping, where only one variation of a crop is grown, a change in the behaviour of pests could lead to devastating impacts on food production.

\section{What can we do about it?}

While this all can sound very worrying, there are things we can do to help reduce our impact. On a large scale, research is being conducted on technology that can be used to reduce emissions linked with agriculture, such as using robots instead of heavy machinery, improved irrigation, and vertical farming where fruit and vegetable are grown on shelves one on top of the other. But what can we do ourselves to reduce the impact of our diet on climate change?

\section{Reducing waste}

One third of the food produced worldwide is either lost or wasted. Food is considered "lost" when it is removed from the food chain before it gets to the consumer, for example food lost through processing ultra-high processed foods or being rejected by supermarkets because of size, shape or colour. Whereas waste refers to the food that is thrown away after reaching the consumer. As the global population is predicted to rise to 9 billion by 2050, it is crucial we start to tackle this issue by reducing our food waste; buying only what you need and freezing foods you won't use before they go off.

There is currently research looking into circular economies for food, which are closed loop systems that aim to maximise resources and reduce as much unnecessary waste as possible. Outside of this, some companies are making profits from these "lost" foods and delivering surplus or rejected fruits and vegetables to homes and offices, or making sauces or smoothies from it. As well as this, there are a variety of apps such as Karma and Too Good to Go, looking to reduce food waste from restaurants, where the public can purchase food from food outlets at a reduced price to prevent it from being thrown away. Another example is OLIO, which help to reduce household waste by allowing members of the public to advertise foods they will not use for someone else to pick up for free.

\section{Reduce meat consumption}

Diets that are considered environmentally friendly are those that are more plant based with a smaller proportion of animal products, particularly vegetarian and vegan diets. These diets also tend to be healthier than those with higher impacts on the environment as they are 
higher in fibre and lower in saturated fat. Therefore, adopting sustainable environmentally friendly diets be an extremely useful way of promoting both public health and planetary health.

A lot of the messages about dietary change for planetary health focus on promoting veganism, removing all animal products from the diet. While it is entirely possible to meet your nutritional requirements on a vegan diet with supplements of fortified foods, it is important to be aware a vegan diet is not always suitable for everyone. Instead, it might be more useful for the majority of people to reduce their meat consumption, particularly red meat. A modelling study by Green and colleagues predicted that a person could reduce their Greenhouse Gas emissions by $40 \%$ if they reduced their red meat consumption by three quarters (6).

\section{Buy locally produced, seasonal foods}

Buying locally produced foods that are in season will help to reduce the transport emissions associated with out of season foods and potentially reduce water usage for crops grown in drought prone countries. However, this would require us to educate ourselves about what fruit and vegetables are in season month to month. Avoiding plastic packaging when possible, as most people are aware, can also help reduce the environmental impact of your diet and many supermarkets have begun trialling refill stations in their stores. Another consideration is limiting consumption of ultrahigh processed foods which require a lot of resources but also leads to food loss.

Despite the challenges linked to making our food systems more sustainable, these actions have the potential to improve not only planetary health but our own health too. Small and sustainable changes such as those mentioned above can help to transform our food systems to reduce their overall impact on the environment, increase demand for more sustainably produced foods and potentially safeguard against some of the effects of climate change on nutrition.

\section{References}

1. Garnett T, Smith P, Nicholson W, Finch J. Food systems and greenhouse gas emissions (Foodsource: chapters). 2016.

2. Office for National Statistics. Food Statistics in your pocket 2017 - Global and UK supply - GOV.UK [Internet]. Food Statistics Pocketbook. 2017 [cited 2020 Mar 10]. Available from: https://www.gov.uk/government/publications/food-statistics-pocketbook2017/food-statistics-in-your-pocket-2017-global-and-uk-supply

3. Cavigli I, Daughenbaugh KF, Martin M, Lerch M, Banner K, Garcia E, et al. Pathogen prevalence and abundance in honey bee colonies involved in almond pollination. Apidologie. 2016 Mar 1;47(2):251-66.

4. Springmann M, Mason-D'Croz D, Robinson S, Garnett T, Godfray HCJ, Gollin D, et al. Global and regional health effects of future food production under climate change: $A$ modelling study. Lancet. 2016 May 7;387(10031):1937-46.

5. Special Report on Climate Change and Land - IPCC site [Internet]. [cited 2020 Mar 21]. 
Available from: https://www.ipcc.ch/srccl/

6. Green R, Milner J, Dangour AD, Haines A, Chalabi Z, Markandya A, et al. The potential to reduce greenhouse gas emissions in the UK through healthy and realistic dietary change. Clim Change. 2015 Jan 26;129(1-2):253-65. 